\title{
Dynamic electricity pricing-Which programs do consumers prefer?
}

\author{
Elisabeth Dütschke ${ }^{\mathrm{a}, *}$, Alexandra-Gwyn Paetz ${ }^{\mathrm{b}}$ \\ ${ }^{a}$ Fraunhofer Institute for Systems and Innovations Research, Breslauer Str. 48, 76139 Karlsruhe, Germany \\ ${ }^{\mathrm{b}}$ Karlsruhe Institute of Technology (KIT), Energy Economics, Hertzstr. 16, 76187 Karlsruhe, Germany
}

H I G H L I G H T S

- Little is known about consumer preferences on dynamic pricing.

- Two studies are conducted to analyze this topic.

- A survey shows that consumers without experience prefer conventional programs.

- Test residents of a smart home were more open to dynamic pricing.

- They also prefer well structured programs.

Keywords:

DSM

Consumer acceptance

Smart homes

\begin{abstract}
A B S T R A C T
Dynamic pricing is being discussed as one method of demand side management (DSM) which could be crucial for integrating more renewable energy sources into the electricity system. At the same time, there have been very few analyses of consumer preferences in this regard: Which type of pricing program are consumers most likely to choose and why? This paper sheds some light on these issues based on two empirical studies from Germany: (1) A questionnaire study including a conjoint analysis design and (2) A field experiment with test residents of a smart home laboratory. The results show that consumers are open to dynamic pricing, but prefer simple programs to complex and highly dynamic ones; smart home technologies including demand automation are seen as a prerequisite for DSM. The study provides some indications that consumers might be more willing to accept more dynamic pricing programs if they have the chance to experience in practice how these can be managed in everyday life. At the same time, the individual and societal advantages of such programs are not obvious to consumers. For this reason, any market roll out will need to be accompanied by convincing communication and information campaigns to ensure that these advantages are perceived.
\end{abstract}

\section{Introduction}

Dynamic pricing has been discussed for some time as an important means of Demand Side Management (DSM). However, so far, few dynamic pricing programs are being offered to consumers (e.g. Energate, 2011) and the potential of dynamic pricing for successful DSM is not entirely clear. In Europe, steps in this direction have been taken by two EC directives in 1996 and 2003; subsequently, national governments as well as utilities throughout Europe have started working towards the introduction and market penetration of dynamic pricing programs. The German government has transposed these directives into national law and has obliged energy providers to offer tariffs that provide incentives for saving electricity as well as for controlling power demand; i.e.

\footnotetext{
*Corresponding author. Tel.: +49-721-6809159.

E-mail addresses: elisabeth.duetschke@isi.fraunhofer.de (E. Dütschke), alexandra-gwyn.paetz@kit.edu (A.-G. Paetz).
}

tariffs that are able to influence consumer behavior. The German law (EnWG §40) explicitly refers to dynamic pricing as one way to fulfill this requirement, as it is assumed that prices influence the demand for electricity. The basic concept behind dynamic pricing is that the consumer price per $\mathrm{kW}$ h varies either by the time of use and/or by the current load at household level.

The need for such actions on the electricity market has to be seen as closely related to changes on the supply side of electricity. Traditionally, the most common rate for pricing electricity in the residential sector in Germany like in many other countries is a fixed rate per $\mathrm{kW} \mathrm{h}$ in combination with a base rate. The price per $\mathrm{kW} h$ remains stable over a longer period (in Germany usually one year). Some utilities also offer day and night rates, which include lower $\mathrm{kW}$ h prices at night, usually in combination with a certain minimum annual electricity demand. These rates were created to match the situation of large scale power plants running on coal or nuclear which resulted in an over supply of electricity at night. In combination with electrical night storage heaters, such rates 
successfully contributed to a more balanced load curve (Klobasa, 2007; Quaschning and Hanitsch, 1999). However, due to an increasing share of fluctuating renewable energy sources like wind and solar, the situation has become more dynamic and supply is likely to become more variable. Dynamic pricing programs have been developed in order to influence demand in such a way that it correlates with the momentary supply. The price variation has two functions: First, low prices are supposed to incentivize demand during times of relatively high supply and, vice versa, high prices help to curb demand during periods of limited supply. Thus, dynamic pricing is supposed to directly influence behavior by providing an economic stimulus. Second, prices also have an informative function: They are a way of communicating with the consumer, e.g. indicating that demand threatens to override supply in a high price period, i.e. a shortage in the resources for generating electricity (cf. Stadler et al., 2004; Faruqui and George, 2002). Thus, in an ideal scenario, varying prices lead to optimal capacity utilization in electricity generation and thereby reduce system costs, making electricity cheaper for the consumer as well (Cousins, 2009). On the supply side, dynamic pricing means that utilities are able to directly transfer part of the financial risk they bear by guaranteeing supply to the consumer. In addition to managing demand in line with supply, it is also hoped that dynamic pricing will help consumers to reduce overall demand, e.g. by becoming more aware of their electricity consumption in a first step and then acting to reduce it in a second.

Up to now, several field trials (see Faruqui and Sergici, 2010; Newsham and Bowker, 2010; Stromback et al., 2011 for reviews) have experimented with dynamic pricing and have been able to prove a certain degree of effectiveness, especially with regard to demand shifts and sometimes also demand reduction. However, so far, dynamic pricing is not common from the perspective of consumers and their market penetration is low (e.g. Bartusch et al., 2011 for Sweden, Moholkar et al., 2004 for US, Energate, 2011 for Germany). Thus, there has not been much experience made with regard to consumer preferences, i.e. we do not know which types of electricity tariffs consumers would prefer if a selection were available on the market. In field trials, consumers are usually not given the option to choose between different types of tariffs, so this type of research only offers a few insights into this issue. However, the question of consumer preferences is crucial, because even if (some) dynamic pricing programs could influence electricity demand in a desired way, this presumes that consumers are also willing to opt for them.

Therefore, this paper aims to investigate consumer preferences regarding dynamic pricing programs. This investigation is based on two empirical studies and combines quantitative and qualita tive social science methods: (1) A conjoint analysis is performed based on data from an online questionnaire and (2) results are presented from a field experiment conducted in a smart home ${ }^{1}$ laboratory. Both studies focus first on identifying the type of dynamic pricing program preferred by the respective respondents; second these analyses are complemented by exploring the broader expectations and evaluations of dynamic pricing programs. Here, especially the experiment in study 2 provides a basis for elaborat ing the motives behind these preferences.

This paper is structured the following way: We start by giving an overview of dynamic pricing programs and their possible specifications. Afterwards we outline the state of research with regard to consumer behavior and preferences. Based on the literature review two research questions are presented. The methods section then presents the research design, sample

${ }^{1}$ The term "smart home" is generally used for linking different separate devices of a household to a network. The term can therefore include aspects of ambient assisted living, entertainment, and security. In our research, we focus on aspects of energy management. descriptions and approaches for analysis for both studies. Subse quently results for both studies are presented ordered according to the two research questions. In the concluding section findings from both studies are then jointly discussed, limitations outlined and conclusions drawn for research, practice and policymakers.

\section{Dynamic pricing programs}

Pricing programs vary in complexity, ranging from the standard rate to more dynamic programs with prices changing flexibly within short periods of time (cf. Gordon et al., 2006; Klobasa, 2007; Wolter and Reuter, 2005). Programs, where the price is fixed in advance for a long period and under a fixed timetable, are called time of use (TOU) programs. Due to its high stability, TOU pricing is sometimes not regarded as a dynamic program (Faruqui and George, 2002). The most dynamic program is real time pricing (RTP), where prices follow market prices more closely, e.g. on an hourly basis (Borenstein, 2002).

In principle, it is possible to imagine a vast range of possible programs: A pricing scheme incorporates several attributes, each of which may vary resulting in a large number of possible combinations (cf. Table 1 ). In the remainder of this section we will outline possible program specifications in more detail based on the attributes listed in Table 1.

Generally, an important categorization for dynamic pricing is the distinction between time varying and load based programs (attribute program rationale in our table). In case of a time varying program, the billed rate per $\mathrm{kWh}$ depends on the point in time when the electricity is demanded; in case of a load based program, the consumer rate depends on the current load level of the household. Of course, these two types can be combined within one program.

Another central attribute of a pricing scheme relates to its dynamics which comprises the definition of rates and the time table (cf. Table 1). In case of time varying pricing, the rate per $\mathrm{kW} h$ varies either regularly or irregularly according to the season, time of day, hour or even shorter periods. The number of rates can be pre defined and limited which is usually the case; however, it is also possible that no price zones are defined in advance. In addition to the number of rates, their time table is part of the definition of the pricing scheme: The duration of a rate can be fixed (e.g. for day and night rates: the night rate could always start at $23 \mathrm{~h}$ and end at $6 \mathrm{~h}$ and thus last $7 \mathrm{~h}$ ). However, the time table could also be dynamic, e.g. include three or more rates of varying starting points and duration.

A further attribute are the rates of a pricing program, i.e. the prices per $\mathrm{kW}$ h. They also define the price spread, i.e. the cost difference between the time zones. Many programs also include fixed expenses for the consumer, e.g. a base rate for connection to the grid.

On top of the attributes outlined so far, pricing programs can also include extraordinary events, such as extremely high penalty costs during critical periods (critical peak pricing CPP; cf. Wolak, $2010)^{2}$ or interruptible rates ${ }^{3}$.

So far, the attributes have been mainly discussed for a time variable pricing program. However, as outlined above, load limits

\footnotetext{
${ }^{2}$ Most research on this model was conducted in the U.S., often in California, following an energy crisis which led to system overloads due to very high peak demand. In this context, this pricing model has shown some effectiveness in reducing demand peaks (cf. Faruqui and George, 2005), but is hardly known in the German market.

3 Interruptible rates are so far only offered to business customers and include the condition that the customer has - upon prenotification - to radically reduce demand. If not, high fees apply. In Germany these tariffs are not common as the regulatory context for them ("Lastabschaltverordnung") is still within the policymaking process.
} 
Table 1

Overview of possible attributes and specifications of residential electricity pricing programs.

\begin{tabular}{ll}
\hline General attributes & Possible specifications \\
\hline $\begin{array}{l}\text { Program rationale } \\
\text { Price zones }\end{array}$ & Rate per kW h depends on time of use or load level or both \\
Time-table & $\begin{array}{l}\text { The number of predefined price zones can vary from one in the case of a standard rate, two in the case of day } \\
\text { and night rates and go up to freely varying zones without predefinition } \\
\text { The time-table defines when and for how long each price zone applies. It can be fixed as in the case of day and } \\
\text { night rates or variable, e.g. change every day or week } \\
\text { The rates per kW h also determine the price spread. They can be fixed, vary between a certain range or vary } \\
\text { without prior limitation } \\
\text { This includes a basic commission fee or lease for technical equipment } \\
\text { Additional events like critical-peak-pricing or low price periods which take place a few times per year }\end{array}$ \\
$\begin{array}{l}\text { Fixed expenses } \\
\text { Extraordinary events }\end{array}$ & $\begin{array}{l}\text { Additional equipment bought/leased/hired by the household to cope with dynamic pricing, e.g. smart meter, } \\
\text { smart appliance, demand automation } \\
\text { Technical equipment }\end{array}$ \\
The possibilities for demand response can be solely manual by the consumer or automated to a varying \\
degree via smart home technologies
\end{tabular}

(or thresholds) are also possible (see program rationale, Table 1 ). The idea behind this is to limit load peaks in order to flatten power demand. If such a load limit is introduced, loads which exceed the limit are usually penalized, i.e. consumers have to pay a higher price per $\mathrm{kWh}$ above the load limit. Obviously, a program can include several thresholds with increasing penalties and/or the exact threshold may vary. And, as pointed out above, time varying and load based programs can be combined.

Other additional attributes can also be relevant, even if they are not actually part of the pricing program itself in a narrow sense. These include the available technical equipment and possibilities for demand response.

Consumers who subscribe to day and night rates usually have two meters installed to count the $\mathrm{kW}$ h. More complex programs also need more advanced measurement to make correct billing possible which is why dynamic pricing is usually combined with smart metering devices. Some kind of information provision (e.g. on current valid rates) is necessary for consumers to be able to adapt their behavior to the price curves or load thresholds of the program for this reason smart meters and additional displays are often considered to be essential (cf. Stadler et al., 2004; Faruqui and George, 2005). Other elements included in smart home concepts are smart appliances and devices for demand automation (demand response). A smart appliance is an electrical household device which is able to react automatically to external signals, e.g. to price signals transmitted by the electricity grid operator (Piette et al., 2006). This could mean, for example, that a refrigerator automatically does most of its cooling in times of low prices, or that a tumble dryer interrupts its cycle and pauses during a peak price period. This means that consumers are able to, at least partially, adapt their demand with little or no extra effort on their part. These smart appliances could also be embedded in a system of demand automation that monitors consumption (smart meter ing) and plans the optimal use of devices (smart appliances) according to the forecasted electricity prices (dynamic pricing).

In addition to the attributes outlined in this section, there are even more possible components of a tariff, e.g. differences in ways and frequency of communication (annual billing or real time information via displays or internet sites). Thus at least from a conceptual point of view consumers could be confronted with a broad variety of programs offered by utilities.

\section{Consumer-oriented research of dynamic pricing}

While the variety of possible programs is vast, only few of them have actually been offered on the market. Over the past few years, several field trials have been conducted to test dynamic pricing in the residential sector. In this section we will review empirical findings on dynamic pricing from consumer oriented research shortly discussing effectiveness of dynamic pricing and in more detail consumer preferences.

As mentioned above, there are two rationales for dynamic pricing as a method of DSM: The first is based on purely economic arguments and assumes that it is possible to control household electricity demand with economic incentives, so that dynamic pricing is seen as a means to control demand curves. The second rationale has its roots in an information deficit model (cf. Hargreaves et al., 2010): It is assumed that consumers lack awareness of and knowledge about their electricity consumption due to its "invisibility" (Fischer, 2007; Hargreaves et al., 2010). If consumers had enough information, they would change their demand, i.e. by reducing or adapting it, and the price per $\mathrm{kW} \mathrm{h}$ is one way of communicating this information (Lo et al., 1991). Based on this second argument, additional feedback (e. g. via in house displays) besides the current rate is therefore a popular element accompanying dynamic pricing in field trials.

Up to now, most of the research conducted has concentrated on analyzing whether dynamic pricing is effective with regard to demand shifting and/or reducing consumption. The literature indicates that especially CPP programs are effective in reducing peak demand; however classical TOU pricing was also found to be effective to some extent (cf. Newsham and Bowker, 2010, as well as Stromback et al., 2011 for reviews). It is less clear how much electricity is actually saved by demand shifting. ${ }^{4}$ Neither is it clear how sustainable the effects are (cf. Stromback et al., 2011). Generally, studies have observed a broad variety of effects, even in similar pricing programs (cf. Newsham and Bowker, 2010; Stromback et al., 2011). Further research therefore emphasizes the role of feedback and information (cf. Darby, 2010).

Most of the research done so far has focused on pilot studies and their participants. These cannot answer the question whether and under which conditions consumers would be willing to subscribe to dynamic pricing and which program they would prefer. Neenan et al. (2002) are among the few researchers trying to shed some light on this issue by asking the non participants of a field test conducted with companies in New York City why they had not signed up for a CPP trial. The most common reasons given were the uncertainty about when critical peaks occur as well as

\footnotetext{
${ }^{4}$ Allcott (2011) evaluated an RTP-scheme and found that participants reduced the demand in high-price periods, but hardly increased it in lower price periods. In contrast, the German MeRegio field test with 1000 households, reported demand increases of up to $17 \%$ in low price periods (Hillemacher et al., 2011).
} 
the load reduction demanded by the program (Neenan et al., 2002). If the firms were allowed to choose between different hypothetical pricing programs, programs with guaranteed pay ments were rated best. This is in line with the results of a representative survey of U.S. American households by Lineweber (2011), who asked questions about the potential benefits of dynamic pricing. Having more control over electricity use and reducing bills as well as total demand were rated as the most important benefits. However, less than $40 \%$ of the consumers were convinced that they would actually experience those benefits.

Based on a laboratory study, Ericson (2011) assumes that individual demand flexibility is predictive of whether or not a consumer is willing to subscribe to a time varying tariff. On an attitudinal level, a German study on consumer attitudes and perceptions reveals that residential consumers are not very open to behavioral changes in their daily routines and require that dynamic pricing is not linked to any reductions in comfort (Paetz et al., 2012). However, consumers also generally report a high acceptance of smart appliances and demand automation systems in surveys (see also Mert et al., 2009 for similar results) which might compensate or at least mitigate the effects on their daily routines.

\section{Research questions}

In sum, the literature suggests that dynamic pricing has some potential to influence peak demand. Dynamic pricing could under favorable conditions also contribute to reducing total electricity consumption. From a consumer's point of view, finan cial gains appear to be important. However, most of these studies are based on data from field trials where participants had little or no choice about which pricing program they wanted to try. There has hardly been any research into which type of pricing program consumers would prefer if they had a choice. This paper aims to bridge this gap by empirically analyzing (1) which pricing pro grams are preferred by consumers and (2) why.

So far, research indicates that consumers are not keen on changing daily routines which makes them favor demand automation (Ericson, 2011; Paetz et al., 2012). At the same time they are not convinced that they will be able to realize potential benefits like saving money or conserving energy (Lineweber, 2011), although they are open to new tariffs on a general level (Paetz et al., 2012). As a result, we assume that consumer choice is based on a high comfort, low cost principle: We expect that consumers will favor a program that is most comfortable for them, i.e. stable, clearly structured and needing as little effort as possible concerning adapting behavior and routines. At the same time, we expect consumers to feel that a new program should offer the chance to save money.

\section{Methods}

In order to analyze our research question and challenge our assumptions, we carried out two studies aimed at shedding light on preferences for dynamic pricing programs: (1) We conducted a conjoint analysis based on an online questionnaire. This study was intended to systematically and quantitatively capture the stated preferences for pricing programs. (2) We analyzed behavioral data and interview material from a field experiment with test residents who lived in a fully equipped smart home laboratory for several weeks. This second study provides scope for exploring the motives behind the preferences regarding a variety of dynamic pricing programs. We give an overview of the procedures in the following. First the research design for study 1 and 2 is outlined subse quently, than the samples of both studies are shortly described in one section. Afterwards the approaches for data analysis are explained one after the other.

\subsection{Design of study 1: Conjoint analysis}

A conjoint analysis is a decompositional procedure which allows the preference for single product attributes (i.e. utilities) to be estimated as well as the relative importance of these product attributes based on global product evaluations (Green and Wind, 1975; Nieschlag et al., 1991). It is assumed that the global evaluation is the (weighted) sum of the attributes' utilities. This implies that the attributes included in the analyses are indepen dent (Backhaus et al., 2006), i.e. that they vary without influencing each other and that they can be evaluated independently of each other.

Dynamic pricing is a concept that is relatively unknown to consumers. A significant share of consumers is not aware of the components of their actual electricity tariff (cp. Gerpott and Mahmudova, 2010). Thus it was necessary to restrict the analyses to a small number of attributes in order to enable survey participants to understand what is expected from them.

For the purpose of this study, three possible attributes of time varying pricing were selected. For each of these attributes, two to three specifications were defined to be included in the analyses (cf. Table 2). Thus, the conjoint analysis consisted of an asymmetric $(3 \times 2 \times 2)$ design resulting in a maximum of twelve possible programs. As basic attributes we chose (1) dynamics, (2) rates defining the price spread, and (3) demand response. Three different specifications of dynamics were included in the analyses as this is the core element of dynamic pricing: fixed rates following a fixed timetable (static), pre defined rates changing on an hourly basis (dynamic), and rates varying freely within a given range (variable). Different kinds of price spread determined by different rates were included as they strongly influence the possible financial impact of a program. In order to spare partici pants the necessity of estimating the financial risk associated with a complex pricing program, we restricted the specification of this attribute to two specifications (low spread/high spread). The specific values given as €ct per $\mathrm{kW}$ h were based on the current $\mathrm{kW}$ h price of $2025 € \mathrm{ct}$ for households. As a third attribute, we included two possibilities of demand response. Possibilities of automated demand response are a complex and very innovative concept that has yet to be realized on a large scale. Thus, we decided to restrict this attribute to a simple yes or no; participants

Table 2

Attributes and the respective specifications for the dynamic pricing programs being studied.

\begin{tabular}{lll}
\hline Attribute & Specification & Description \\
\hline Dynamics & Static & 3 price levels following a fixed timetable (TOU) \\
& Dynamic & 3 price levels, changing on an hourly basis (RTP) \\
& Variable & Prices vary freely within a given range (RTP) \\
Rates: price spread & Low & Between 15 and $25 € c t / k W h$ \\
Demand response & High & Between 10 and $35 € c t / k W h$ \\
& Manual & Manual control of household appliances, prices are shown on an in-house display \\
& Automated & Smart appliances which react automatically to price information
\end{tabular}


were given a short explanation of what automated demand response could include and they were asked to imagine that they had all the necessary equipment.

These pricing programs were subjected to pairwise compar isons by the respondents and evaluated on a seven point scale. Participants indicated their opinion on this scale, which ranged from a clear preference for one of the two programs presented (by choosing 1 or 7 ) to stating a neutral opinion (by choosing 4).

Eight of the twelve possible programs were selected to be evaluated by the respondents in the survey using the guidelines for orthogonal designs (cf. Addelman, 1962; Green, 1974). The reduced design was applied in order to lower the effort required from participants. Filling in a conjoint survey is time consuming, especially, like in our case, if the subject on which choices are to be made is not an everyday activity. The order in which the programs were presented to the participants was changed randomly to avoid order effects.

In addition to the conjoint analysis, the questionnaire included items asking for socio demographic data as well as some asking for possible effects and a general evaluation of dynamic pricing and prior knowledge of energy tariffs including the following question: Do you think that dynamic pricing contributes to (1) saving energy (2) a higher awareness of energy (3) implement ing renewable energy sources (4) saving money. Respondents answered on a scale from yes/to some extent/a bit/no. Addition ally, respondents were asked whether they would prefer a standard rate or dynamic pricing for their own household.

To ensure the comprehensibility of the questionnaire, earlier versions were discussed with academic experts as well as friends and family. A pretest with a small student sample was used to analyze whether participants were able to see the differences between the dynamic pricing programs, i.e. whether different evaluation patterns were apparent.

\subsection{Design of study 2: Experimental analysis}

While study 1 reveals general preferences for a larger sample of consumers, the second study concentrates on analyzing the prefer ences of consumers already familiar with dynamic pricing programs as well as providing a more detailed analysis of the motives behind certain preferences. An experimental approach was applied and test living phases were conducted with a small sample using the Energy Smart Home Lab (ESHL) on KIT's campus (see Allerding and Schmeck, 2011 for a detailed technical description of the house). The smart home setting combines the advantages of a laboratory experiment and a field trial: On the one hand, the ESHL ensures a certain degree of stability, because the researched technologies can be controlled, interventions are quickly possible (e.g. in the case of technical problems) and the experimental set up can be reproduced. On the other hand, the ESHL resembles a field trial, because it is built as a fully equipped and functioning $60 \mathrm{~m}^{2}$ household, in which two test residents can live a normal everyday life. In this setting we conducted two test living phases with four test residents: phase I with a duration of eight and phase II of five weeks. During this time we tested a variety of dynamic pricing programs based on study 1 programs. After an introductory week with a conventional standard rate in each test living phase, different dynamic pricing programs (cf. Table 3 for an overview) were introduced on a weekly basis. Program A is a conventional standard rate which defines the baseline, program B corresponds to a TOU program, programs $\mathrm{C}$ to $\mathrm{H}$ to RTP. After some time the test residents were also given the chance to use additional equipment to enable demand automation.

During their stay, the test residents were able to see the prices for electricity per $\mathrm{kWh}$ as displayed in Table 3 . Since the test residents did not have to pay for their energy expenses while staying in the smart home, we designed a bonus malus system to provide a financial incentive. For each $\mathrm{kW} \mathrm{h}$ consumed at the respective lowest rate, the test residents gained one point; they lost one for each $\mathrm{kWh}$ con sumed at the respective highest rate or for each $\mathrm{kW} \mathrm{h}$ above the load limit. Each point was worth $0.5 €$. If the residents finished their stay with a positive balance, the corresponding amount of money was paid out at the end of the test living phase.

We conducted two in depth interviews each lasting an hour in each phase: one after the first half of the test living period and the other at the end of the experiment. In addition, the test residents wrote about their experiences in an online blog during the test living period. We were therefore able to collect a rich amount of data regarding the motives for and barriers to accepting a program. Extensive measurement equipment in the ESHL enabled residents' reactions to the program to be recorded, i.e. whether or not they adapted their electricity demand.

\subsection{Sample description for both studies}

For both studies, the sample was recruited via the internet (social media, mailing lists etc). The four people living in the smart home were preselected after collecting the names of interested individuals using a screening questionnaire and finally chosen after a house tour. We selected participants who were interested in the subject, but had little or no prior knowledge of DSM and respective technologies. In both studies (see Table 4), participants were relatively young and highly educated. Thus the sample is not representative for the German population a limitation that has to be kept in mind when interpreting the results.

\subsection{Approaches for data analysis}

\subsubsection{Approach for study 1: Conjoint analysis}

The data from the conjoint survey was analyzed by applying a linear multiple regression model to determine the utilities. Using a dummy coding, one of the possible specifications of each attribute

Table 3

Pricing programs tested during the experimental study.

\begin{tabular}{|c|c|c|c|c|c|c|c|c|}
\hline Program & A & B & $\mathrm{C}$ & $\mathrm{D}$ & E & $\mathrm{F}$ & G & $\mathrm{H}$ \\
\hline Living phases & $\mathrm{I} / \mathrm{II}$ & I & I & $\mathrm{I} / \mathrm{II}$ & $\mathrm{I}$ & II & & \\
\hline Program rationale & Base-line & \multicolumn{4}{|l|}{ Time } & \multicolumn{3}{|c|}{ Time and load } \\
\hline Dynamics & - & & & & & & & \\
\hline Price zones & 1 & 2 fixed zones & \multicolumn{2}{|c|}{3 varying zones } & 5 varying zones & \multicolumn{3}{|c|}{3 varying zones with additional load limits } \\
\hline Load limit $[\mathrm{kW}]$ & - & - & - & - & - & 6 & 4 & $2.5-6$ \\
\hline Time-table & \multicolumn{2}{|c|}{ Varying weekly } & \multicolumn{6}{|c|}{ Varying daily } \\
\hline \multirow[t]{5}{*}{ Rates [€ct/kW h] } & & & & 7 & 7 & 7 & 7 & 7 \\
\hline & & 12 & 17 & & 14 & & & \\
\hline & 22 & & 22 & 22 & 22 & 22 & 22 & 22 \\
\hline & & 28 & & & 30 & & & \\
\hline & & & 37 & 37 & 37 & 37 & 37 & 37 \\
\hline Technical equipment & \multicolumn{5}{|c|}{ Smart meter; touch-screen-display; iTouch } & \multicolumn{3}{|c|}{ appliances; demand automation } \\
\hline Demand response & Manual & & & Manual & Demand automa & tion & & \\
\hline
\end{tabular}


Table 4

Sample descriptions for both studies.

\begin{tabular}{lll}
\hline & $\begin{array}{l}\text { Study 1 conjoint } \\
\text { analysis }\end{array}$ & $\begin{array}{l}\text { Study } 2 \text { smart } \\
\text { home experiment }\end{array}$ \\
\hline Sample size & 160 & 4 \\
Mean participant age & $\begin{array}{l}29 \text { years } \\
61 \% \text { male }\end{array}$ & $\begin{array}{l}27 \text { years } \\
\text { Gender }\end{array}$ \\
$\begin{array}{ll}39 \% \text { men and } 2 \text { women } \\
\text { Education }\end{array}$ & $67 \%$ university degree & 3 with university degree \\
\hline
\end{tabular}

was used as a baseline (coded zero). Thus a positive regression coefficient indicates the positive influence of an attribute on the overall evaluation in relation to the baseline attribute specification (cf. Orme, 2010). A negative coefficient indicates a lower evalua tion than the baseline attribute specification. When interpreting the utilities, it has to be kept in mind that they are only mean ingful in relation to the respective baseline and cannot be compared between attributes. The relative importance of each attribute is estimated by calculating its relative importance on an individual level and aggregating it to obtain an average value. The individual relative importance is estimated by dividing the utility range for one attribute, i.e. from minimal to maximal utility of this attribute, by the full range.

\subsubsection{Approach for study 2: Field experiment}

The in depth interviews from study 2 were recorded and then transcribed literally. Using the qualitative content analysis method described by Mayring (2000), the transcripts were coded together with the blog entries. The behavioral data based on the real time electricity metering was analyzed statistically.

\section{Which pricing programs are preferred by consumers?}

In the next sections, we first present the results from both studies about which programs are preferred by consumers. Then we outline our empirical findings on the possible motives for these preferences and other consumer perceptions of dynamic pricing programs. An overall discussion of the findings follows after the presentation of all results.

\subsection{Study 1: Conjoint analysis}

\subsubsection{Utilities}

Table 5 provides an overview of the resulting utilities in relation to the respective baseline categories.

Both specifications of the dynamics attribute have significant negative coefficients, i.e. participants prefer the baseline category which is the static pricing program with fixed time zones (TOU). Furthermore, dynamic pricing is preferred to variable pricing. With regard to the price spread defined by the rates, participants preferred a low spread as indicated by the significant negative coefficient for the high spread specification. For demand response, participants rated demand automation preferable to a manual system.

\subsubsection{Relative importance}

The average relevance of the programs' attributes is shown in Table 6.

The dynamics of a program turn out to be the most relevant, i.e. the specification of this attribute has the highest influence on the overall evaluation of the respective program. The price spread is the least important, in other words, whether a program includes a
Table 5

Utilities of the analyzed attributes.

\begin{tabular}{llllll}
\hline Attribute & Specification & Coeff. & S.D. & $\mathrm{t}$ & Sig. \\
\hline \multirow{2}{*}{ Dynamics } & Static & 0 & - & - & - \\
& Dynamic & -.383 & .072 & -5.300 & $<0.01$ \\
& Variable & -.579 & .088 & -6.547 & $<0.01$ \\
\multirow{2}{*}{ Rates: price spread } & Low & 0 & - & - & - \\
& High & -.126 & .057 & -2.204 & $<0.01$ \\
Demand response & Manual & 0 & - & - & - \\
& Automated & .565 & .057 & 9.900 & $<0.01$ \\
\hline
\end{tabular}

Table 6

Relative importance of pricing programs' attributes

\begin{tabular}{ll}
\hline Attribute & Relative importance [\%] \\
\hline Dynamics & 44 \\
Rates: price spread & 22 \\
Demand response & 33 \\
\hline
\end{tabular}

high or low spread of $\mathrm{kW}$ h prices has the least relevance for the overall evaluation of a program.

\subsection{Study 2: Field experiment}

\subsubsection{Data on electricity demand}

The Table 7 summarizes the performance data for selected programs. The better the reaction of the test residents to the program (i.e. the higher the share of electricity consumed during low price periods), the better the program was understood and accepted. Even though the selected weeks are not fully compar able, because the two living phases were conducted during different seasons with different inhabitants, some general tenden cies are still apparent:

- First of all, we observed that the residents became increasingly familiar with the concept of dynamic pricing over the course of the test living phase, acquired a better understanding of the respective program and were better able to integrate them into their daily lives, i.e. behave accordingly.

- A large number of price zones offered more possibilities to shift consumption to low price zones, but also carried the risk of entering the high price time zones more often.

- Demand automation ensured that better use was made of dynamic pricing with regard to both load shifting and cost savings.

- Load limits did not seem to have an effect on individual consumption.

\subsubsection{User behavior and perceptions}

In both phases the two flatmates started to coordinate the use of devices and discuss the $24 \mathrm{~h}$ rate forecast. The possibility to react flexibly to the rates was limited by the test residents' working hours. Three of the four were fully employed; one of them worked shifts. This meant that sometimes the test residents were simply not able to make use of low rates, especially before demand automation was enabled. At the same time, the will ingness to use appliances at the very start or end of a day (before 7 a.m. and after 10 p.m.) was low; however, this also depended on the function provided by the respective appliance: while some appliances were mainly operated during low price periods (e.g. dishwasher, the tumble dryer and washing machine), the usage 
Table 7

Electricity demand during example weeks of the test-living phases and under different programs of electricity pricing.

\begin{tabular}{|c|c|c|c|}
\hline Program & $\mathrm{D}$ & $\mathrm{D}$ & $\mathrm{H}$ \\
\hline Living hase & I & II & II \\
\hline Dynamic Pricing Program & RTP 3 price levels (\%) & $\begin{array}{l}\text { RTP } 3 \text { price levels, demand automation } \\
(\%)\end{array}$ & $\begin{array}{l}\text { RTP with load limit } 3 \text { price levels, demand automation } \\
(\%)\end{array}$ \\
\hline Demand at high rate $(37 € c t / k W h)$ & 29 & 22 & 25 \\
\hline Demand at medium rate $(22 € c t / k W h)$ & 33 & 31 & 29 \\
\hline Demand at low rate $(7 € c t / k W ~ h)$ & 38 & 47 & 46 \\
\hline $\begin{array}{l}\text { Cost savings (compared to standard } \\
\text { rate) }\end{array}$ & 7.2 & 21.4 & 16.2 \\
\hline
\end{tabular}

Note. The share of each rate's validity (high, medium, low) was identical, i.e. if participants had consumed electricity regardless of the rate, respective shares of around $33 \%$ were to be expected.

of all other appliances (e.g. lighting, stove, TV) was hardly adapted to varying rates, because of their entertainment and comfort functions.

This comfort aspect also came into play when testing load limits. As seen above, these had no effect on consumption: the test residents simply refused to try to stay below certain load limits because they felt it would constrain their lifestyle too much.

In contrast to study 1 , the test residents did not perceive a significant difference between the tested price spreads. Possibly, because of the design of the bonus malus system, they were more interested in the rate level (low, medium, high) than in the specific price per $\mathrm{kWh}$.

\subsubsection{Preferences}

When asked about their preferences regarding the different programs, three out of four test residents stated that they preferred dynamic pricing to static pricing. Besides this general preference, the test residents in both phases did not like complex programs. While in phase I one of the two residents was not able to state a clear preference for either TOU or RTP (with three price levels), the other test resident clearly favored a static program. A feedback system and a price information device were seen as preconditions for choosing dynamic pricing; short payback times on investments (around two years) were also viewed as important.

The test residents in phase II did not like load limits and preferred RTP for their own homes even after they were shown what a TOU would look like. One test resident felt that he would be better able to obtain a share of low market prices with RTP than with a TOU price calculated in advance for one year. However, both felt that rates should be somehow subject to a cap, fearing that rates could stay constantly high in extreme situations on the market (e.g. in case of longer periods of unusual weather condi tions which restrict renewable generation from wind and solar power). In line with their desire to save money, both residents also preferred higher price spreads to lower price spreads, as long as there was a cap on the highest price zone.

If the price difference were only 2 Cents, it wouldn't matter. There would be no motivation at all. I'd then turn the tumble dryer on immediately rather than waiting and saving 4 Cents. But if we were talking about 20 or 30 Cents, I would really care about that. (phase II)

\section{What are the possible explanations for these preferences?}

\subsection{Study 1: Conjoint analysis}

Further questions accompanying the conjoint analysis items provide additional information about which effects participants associate with dynamic pricing. It turns out that the respondents are not completely convinced about the effectiveness of dynamic
Do you think that dynamic pricing contributes to

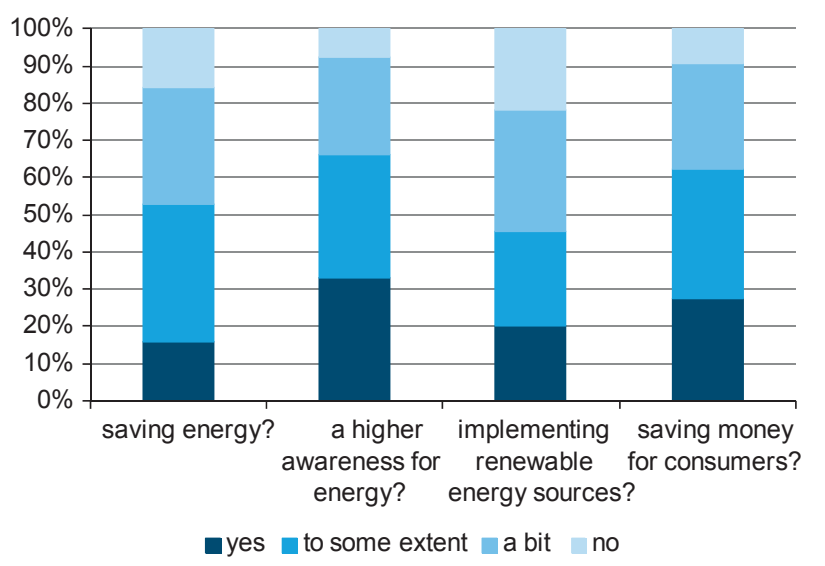

Fig. 1. Evaluations of dynamic pricing programs

pricing (Fig. 1). 53\% agree that dynamic pricing might contribute to saving energy, while $47 \%$ think that it will not make much difference (summing up the categories 'yes' and 'to some extent' as well as 'a bit' and 'no', respectively). Thus the sample is obviously divided on this issue. A majority of $67 \%$ agrees with the proposition that dynamic pricing might be useful in enhancing awareness of energy use, while the remaining third remains critical. $46 \%$ expect dynamic pricing could support the integration of electricity from renewable energy sources into the grid, and another $26 \%$ expect this to some extent. Saving money seems realistic to $63 \%$, but not to $37 \%$.

Thus, the advantages of dynamic pricing are not obvious to the participants. This is also mirrored in the answers to an additional general question on preferences: When participants were asked whether they would prefer dynamic pricing or a standard rate, a vast majority of $69 \%$ said they prefer the standard rate, $25 \%$ would like dynamic pricing, $7 \%$ do not provide an answer. If the answers to this question are regressed on the evaluations of the four items concerning the possible effects of dynamic pricing, it turns out that only saving energy is significantly related to the preference for dynamic pricing or a standard rate (binary logistic regression model, $\chi^{2}=14.0$, d.f. $=4, p<.01$, Nagelkerke's $R^{2}=.13$ ). However, because the share of explained variance is small, the questions on effects only seem able to capture a small percentage of the factors influencing the preference for a dynamic or a standard rate.

\subsection{Study 2: Field experiment}

Cost savings were an important motive for all four participants when explaining their preferences for a particular program. The cost saving expectation for a dynamic pricing program was between 50 and $150 €$ per year without considering investments in smart meters or other devices. While this expectation is similar 
to previous research results (cf. Paetz et al., 2012), it is fairly high: During both test living phases, the residents saved around 3\% (phase I) and 6.5\% (phase II) on electricity costs in comparison to a standard rate. Projecting this to a full year, the savings would add up to around 20 (phase I) and $60 €$ (phase II), respectively; thus, even in an optimal case, just equal to the minimum savings expected.

Environmental issues were an important motive for two of the four test residents. The idea of being able to better integrate electricity generated by renewable resources into the system was especially appealing to them. Accordingly, both wished that more information would be provided about the electricity generation mix.

Part of the participants' motivation for load shifting during the study was due to the experimental setting in the smart home and the fun of trying to cope with dynamic pricing. If dynamic pricing was discussed in relation to their usual household, cost savings were the overriding motive. The test residents also showed a high level of interest in demand automation options for their household but want the costs for the necessary investments to decrease and smart appliance standards to be set.

I like the variable prices. If I could let's say save at least $50 €$ per year, then I would choose it for my home, too. On the other hand $50 €$, that is not even the price of one cocktail every month. Well, anyway, if I can save, then I take it. (phase I)

\section{Discussion and Implications}

In the following section the findings from both studies will be integrated and discussed. The discussion is followed by an analysis of the limitation of this paper before implications for politics and utilities are outlined.

\subsection{General discussion}

Although dynamic pricing has been being discussed for some time now as a possible means for DSM and several field trials have been initiated, so far hardly any research has been done on analyzing consumers' views of these programs. This paper aimed to contribute to closing this gap by focusing on two questions: Which programs are preferred by consumers and why?

Regarding the preferred pricing program, we found that parti cipants in our first study favored programs where price levels follow a fixed timetable (TOU), have a low price spread and include demand automation while the dynamics are the most important attribute for the evaluation of the program. In general, the vast majority of study 1 participants favor a standard rate over any dynamic pricing program. To some extent these findings stand in contrast to the preferences expressed by the participants of the second study: having lived in a smart home environment, 3 out of 4 preferred a simple RTP to a TOU, but combined with demand automation. One possible explanation for the divergence in pre ferences might be the practical experience made by the smart home residents who found out that living with RTP can be managed with no loss of comfort if the automation system supports demand response; an issue that was probably not apparent to the inexperienced survey participants. And on top of this, being able to try out different programs seems to make the residents more open to new programs.

The questionnaire study also revealed that potential positive effects of dynamic pricing like saving energy, increasing awareness of energy consumption, integrating more renewable energy sources and saving money are only partially accepted, i.e. a significant share of respon dents had doubts whether these would really be possible. When relating the evaluations to the willingness to prefer a dynamic pricing program to a conventional one, it turns out that only saving energy is predictive for this variable; i.e. those respondents expecting dynamic pricing to help save energy are more likely to favor it over a standard rate. For the test residents, the chance to save money was the most important motivation and for some of them environmental issues as well. In relation to cost savings, it is important to note that the residents' expectations were higher than the savings actually realized through demand management at least under the conditions given in our test home.

Overall, the results indicate some support for our high comfort, low price assumption: in general our participants were open to demand automation which controls electricity demand in accor dance with price dynamics without forfeiting comfort. With regard to price issues, the participants of the first study preferred a small price spread, i.e. minimizing financial risk, while partici pants in the second study focused more on the chance to save money, i.e. were more open to higher price spreads and more volatile dynamics but also requesting a cap as a kind of safety net in extreme cases.

\subsection{Limitations}

Before discussing implications and drawing conclusions, it is necessary to look at the limitations of the two studies. Both suffer from limitations related to the sample under study. The partici pants of the survey (study 1) are not representative for the German population, being younger, better educated, and relatively well informed about the issues being researched. Therefore, it can be argued that this sample is likely to be more open to dynamic pricing than other groups. However, this argument cannot be supported by empirical findings and should therefore be used carefully. The same problem applies to the smart home study where in addition to this the number of participants was small. For these reasons, it is difficult to predict the generalizability of the results.

With regard to dynamic pricing programs, we were only able to analyze a small selection of the vast range of possible programs. When choosing the programs to be included, we tried to focus on programs that are often being discussed. At the same time, we aimed at selecting programs that are relatively easy to understand as the participants in both studies only had a very limited time to do their evaluation (study 1 ) or adapt to the new conditions (study 2). Choosing an electricity tariff is not an everyday activity; most people are only confronted with having to make this choice on a few occasions during their lifetime. This was also supported by observations made in the smart home study, where test residents always needed some time to adapt to a new program and, at the beginning, to get used to monitoring their energy consumption and prices for the first time as part of everyday life.

\subsection{Implications for politics and utilities}

One important reason why dynamic pricing has received considerable attention from governments is that it is seen as a possible way to align electricity demand and supply in the face of a changing, more fluctuating supply system. Based on our results, it does not seem likely that a considerable share of consumers is willing to voluntarily subscribe to dynamic pricing at least our participants preferred to stick to a traditional standard rate. These results also have to be seen in the light of findings that consumers are reluctant to change their electricity supplier (cp. Brennan, 2007), i.e. seem to have a preference not to choose. This points to the need that if dynamic pricing is supposed to significantly support a transformation of the energy system, it will need to be heavily promoted and accompanied by informatory measures. This includes making transparent how these programs contribute to 
enhancing sustainability and ensuring stability of the electricity system. Thus, the diffusion of dynamic pricing may ask for regulatory enforcement. However, from a political point of view, the question remains whether dynamic pricing is then a reason able way to manage demand or whether other approaches are more promising and more easily accomplished. At this point, further research is also needed that compares means of DSM from a multidisciplinary perspective. This involves a concurrent analysis of technical feasibility, costs and profitability for all actors involved as well as individual behavioral aspects and societal acceptance.

If dynamic pricing is supposed to be promoted to consumers, we would, based on our findings, advice utilities to start with simple, i.e. transparent and predictable, programs, i.e. with little dynamics. With increasing complexity of tariffs we would recom mend combining them with further services and products. This includes supporting technologies and services such as meters and in home displays as well as smart household appliances and demand automation as additional options which improve conve nience. Moreover, technology will be needed to comfortably use and monitor such a smart home system. On the one hand, these combined offers could support the promotion and the acceptance of dynamic pricing. On the other hand, such offers could even constitute a new and profitable area of business for utilities.

However, a successful market roll out of such programs may be hampered by the fact that consumers expect short payback periods for their investments and relatively high savings. Thus, as pointed out before, it will be crucial to provide accompanying information on the benefits. The positive individual and societal effects do not seem to be obvious to consumers which points to the need to provide extensive and clear information including how to ensure that individuals as well as society as a whole can realize these benefits.

\section{Acknowledgements}

We gratefully acknowledge funding for the studies presented in this paper by the German Federal Ministry of Economics and Technology as part of the projects MeRegioMobil and iZeus. We would like to thank Michael Unterländer who played a crucial role in conducting the survey for the Conjoint Analyses and also supported data analyses. A special thanks goes to the test residents of our field experiment as well as to Karla Münzel who transcribed all interviews. We also thank Silvester van Koten and Falko Ueckerdt for their valuable comments on an earlier version of this paper presented at the YEEES PhD workshop 2012 as well as the two anonymous reviewers.

\section{References}

Addelman, Sidney, 1962. Orthogonal main-effect plans for asymmetrical factorial experiments. Technometrics 4 (1).

Allcott, H., 2011. Rethinking real-time electricity pricing. Ressource and Energy Economics 33 (2011), 820-842.

Allerding, F. Schmeck, H. (2011): Organic Smart Home-architecture for energy management in intelligent buildings. In: Workshop Organic Computing as part of ICAC 2011.

Backhaus, K., Erichson, B., Plinke, W., Weiber, R., 2006. Multivariate Analysemethoden-Eine anwendungsorientierte Einführung. Springer-Verlag, Berlin, Heidelberg.

Bartusch, C., Wallin, F., Odlare, M., Vassileva, I., Westler, L., 2011. Introducing a demand-based electricity distribution tariff in the residential sector: demand response and customer perception. Energy Policy 39 (9), 5008-5025.

Borenstein, S., 2002. The trouble with electricity markets: understanding California's restructuring disaster. The Journal of Economic Perspectives 16 (1) 191-211. (21).
Brennan, T.J., 2007. Consumer preference not to choose: Methodological and policy implications. Energy Policy 35, 1616-1627.

Cousins, T., 2009. Using time of use (TOU) tariffs in industrial, commercial and residential applications effectively. TLC Engineering Solutions.

Darby, S., 2010. Smart metering: what potential for householder engagement? Building Research and Information 38, 442-457.

Energate (2011). Daily News, Energate Messenger No. 119, 22.06.2011.

Ericson, T., 2011. Household's self-selection of dynamic electricity tariffs. Applied Energy, 201188 (7), 2541-2547.

Faruqui, A., George, S., 2002. The value of dynamic pricing in mass markets. The Electricity Journal 2002, 45-55.

Faruqui, A., George, S., 2005. Quantifying customer response to dynamic pricing. The Electricity Journal 18 (4), 53-63.

Faruqui, A., Sergici, S., 2010. Household response to dynamic pricing of electricity: a survey of 15 experiments. Journal of Regulatory Economics 38 (2010), 193-225.

Fischer, C. (2007). Influencing electricity consumption via consumer feedback. In: Proceedings of the ECEEE 2007 Summer Study. pp. 1873-1884.

Gerpott, T.J., Mahmudova, I., 2010. Determinants of price mark-up tolerance for green electricity-lessons for environmental marketing strategies from a study of residential electricity customers in Germany. Business Strategy and the Environment 19, 304-318.

Gordon, K., Olson, W.P., Nieto, A.D., 2006. Responding to EPAct 2005: looking at smart meters for electricity. Time-based rate structures, and net metering. Edison Electric Institute (EEI), Washington, D.C.

Green, Paul E., 1974. On the design of choice experiments involving multifactor alternatives. The Journal of Customer Research 1, 61-68.

Green, P.E., Wind, Y., 1975. New way to measure consumer judgments. Harvard Business Review, 106-117.

Hargreaves, T., Nye, M., Burgess, J., 2010. Making energy visible: a qualitative field study of how householders interact with feedback from smart energy monitors. Energy Policy 38, 6111-6119.

Hillemacher, L.; Eer-Frey, A.; Fichtner, W. (2011). Preis- und Effizienzsignale im MeRegio Smart Grid Feldtest-Simulationen und erste Ergebnisse. In: Proceedings of the seventh Internationale Energiewirtschaftstagung. Vienna.

Klobasa, M. (2007). Dynamische Simulation eines Lastmanagements und Integration von Windenergie in ein Elektrizitätsnetz auf Landesebene unter regelungstechnischen und Kostengesichtspunkten. Dissertation ETH Zürich, Nr. 17324.

Lineweber, D.C., 2011. Understanding residential customer support for - and opposition to - smart grid investments. The Electricity Journal (24) 8 (2011), 92-100.

Lo, K.L., McDonald, J.R., Le, T.Q., 1991. Time-of-day electricity pricing incorporating elasticity for load management purposes. International Journal of Electrical Power \& Energy Systems 13 (4), 230-239.

Mayring, P., 2000. Qualitative content analysis. Forum: Qualitative Social Research 1 (2).

Mert, W., Watts, M., Tritthart, W. (2009). Smart domestic appliances in sustainable energy systems-consumer acceptance and restrictions. In: Proceedings of the ECEEE 2009 Summer Study. pp. 1751-1761.

Moholkar, A., Klinkhachorn, P., Feliachi, A., 2004. Effects of dynamic pricing on residential electricity bill. Power Systems Conference and Exposition, 2004. IEEE PES 2, 1030-1035.

Neenan, B., Boisvert, R.N., Cappers, P.A., 2002. What makes a customer price responsive? The Electricity Journal, April 2002, 52-59.

Newsham, G.R., Bowker, B.G., 2010. The effect of utility time-varying pricing and load control strategies on residential summer peak electricity use: a review. EnergyPolicy 38 (2010), 3289-3296.

Nieschlag, R., Dichtl, E., Hörschgen, H., 1991. Marketing, 16. Duncker und Humblot, Auflage, Berlin

Orme, B., 2010. Interpreting the Results of Conjoint Analysis. Research Publishers, Madison.

Paetz, A.-G., Dütschke, E., Fichtner, W., 2012. Smart homes as a means to sustainable energy consumption: a study of onsumer perceptions. Journal of Consumer Policy 35 (1), 23-41.

Piette, M.A., Watson, D., Motegi, N., Kiliccote, S., Xu, P., 2006. Automated Critical Peak Pricing Field Tests: Program Description and Results. Lawrence Berkeley National Laboratory, Berkeley.

Quaschning, V., Hanitsch, R., 1999. Lastmanagement einer zukünftigen Energieversorgung-Integration regenerativer Energien in die Elektrizitätsversorgung. BWK - Brennstoff Wärme Kraft 10 (1999), 64-67.

Stadler, M.; Auer, H.; Haas, R. (2004). Die Bedeutung von dynamischen Tarifmodellen und neuer Ansätze des Demand-Side-Managements als Ergänzung zu Hedging-Manahmen in deregulierten Elektrizitätsmärkten. Österreichische Nationalbibliothek, Nr. 7895.

Stromback, J.; Dromacque, C., Yassin, M.H. (2011): The Potential of Smart Meter Enabled Programs to Increase Energy and System Efficiency-A Mass Pilot Vomparison. VaasaETT Global Energy Think Tank.

Wolak, F. (2010). Residential Customer Response to Real-Time Pricing: The Anaheim Critical Peak-Pricing Experiment. Department of Economics, Stanford.

Wolter, D. Reuter, E. (2005). Preis- und Handelskonzepte in der StromwirtschaftVon den Anfängen der Elektrizitätswirtschaft zur Einrichtung einer Strombörse. Deutscher Universitätsverlag, Wiesbaden. 


\section{Repository KITopen}

Dies ist ein Postprint/begutachtetes Manuskript.

Empfohlene Zitierung:

Dütschke, E.; Paetz, A.-G.

Dynamic electricity pricing - Which programs do consumers prefer? 2013. Energy Policy, 59.

doi:10.554/IR/1000045138

Zitierung der Originalveröffentlichung:

Dütschke, E.; Paetz, A.-G.

Dynamic electricity pricing - Which programs do consumers prefer? 2013. Energy Policy, 59, 226-234.

doi:10.1016/j.enpol.2013.03.025 